\title{
Impact of regional haze towards air quality in Malaysia: a review
}

\begin{abstract}
Haze is a common phenomenon afflicting Southeast Asia (SEA), including Malaysia, and has occurred almost every year within the last few decades. Haze is associated with high level of air pollutants; it reduces visibility and affects human health in the affected SEA countries. This manuscript aims to review the potential origin, chemical compositions, impacts and mitigation strategies of haze in Malaysia. "Slash and burn" agricultural activities, deforestation and oil palm plantations on peat areas, particularly in Sumatra and Kalimantan, Indonesia were identified as the contributing factors to high intensity combustions that results in transboundary haze in Malaysia. During the southwest monsoon (June to September), the equatorial SEA region experiences a dry season and thus an elevated number of fire events. The prevailing southerly and south-westerly winds allow the cross-boundary transportation of pollutants from the burning areas in Sumatra and Kalimantan in Indonesia, to Peninsular Malaysia and Malaysian Borneo, respectively. The dry periods caused by the El Niño Southern Oscillation (ENSO) prolong the duration of poor air quality. The size range of particulate matter (PM) in haze samples indicates that haze is dominated by fine particles. Secondary inorganic aerosols (SIA, such as SO42- and NH4+) and organic substances (such as levoglucosan, LG) were the main composition of PM during haze episodes. Local vehicular emissions and industrial activities also contribute to the amount of pollutants and can introduce toxic material such as polyaromatic hydrocarbons (PAHs). Haze episodes have contributed to increasing hospital visits for treatments related to chronic obstructive pulmonary diseases, upper respiratory infections, asthma and rhinitis. Respiratory mortality increased $19 \%$ due to haze episodes. Children and senior citizens are more likely to suffer the health impacts of haze. The inpatient cost alone from haze episodes was estimated at around USD 91,000 per year in Malaysia. Almost all economic sectors also experienced losses, with the heaviest losses in the agriculture and tourism sectors. This review suggests several ways forward to reduce haze episodes in SEA and Malaysia. These include economic approaches, research collaborations and science-policy interface. Improving forecasting capabilities can help reduce response time to burning events and subsequently reduce its impacts. Lastly, commitment and involvement by individuals, government agencies, and the entrepreneurial private sectors are crucial to reduce biomass burning (BB) and haze episodes in SEA.
\end{abstract}

Keyword: Biomass burning; Haze episode; El Niño; Particulate matter; Health impact; Southeast Asia 